\title{
Perspectivas para el desarrollo de vacunas e inmunoterapia contra cáncer cervicouterino*
}

Liliana Guzmán-Rojas, M. en C.,(1)

Juan Manuel Alcocer-González, M.C., ${ }^{(2)}$ Vicente Madrid-Marina, M.C., Dr. en C.(1)

\section{Guzmán-Rojas L, Alcocer-González JM, Madrid-Marina V. Perspectivas para el desarrollo de vacunas e inmunoterapia contra cáncer cervicouterino. Salud Publica Mex 1 998;40:38-46.}

\section{Resumen}

El cáncer cervicouterino representa un grave problema de salud pública, debido a la asociación de la neoplasia con el virus del papiloma humano; actualmente se realizan estudios usando estrategias dirigidas a combatir este patógeno, mediante vacunas, que podrían ser de gran utilidad para el control de la progresión de la enfermedad. El estudio tanto de la inmunología humoral como celular ha servido para el desarrollo de vacunas. Así, la utilización de partículas virales sintéticas para el estudio de anticuerpos neutralizantes y el uso de proteínas tempranas virales, entre otras, para la inducción de inmunidad mediada por células, han sido la pauta para realizar estudios que dirijan la respuesta inmune para prevenir la infección celular tanto hacia células infectadas no transformadas como hacia células transformadas viralmente con resultados favorables.

Palabras clave: neoplasmas del cuello uterino; vacunas; inmunoterapia; México

\author{
Guzmán-Rojas L, \\ Alcocer-González JM, Madrid-Marina V. \\ Perspectives for vaccines \\ and immunotherapy \\ against cervical cancer. \\ Salud Publica Mex I 998;40:38-46.
}

\section{Abstract}

Cervical cancer represents a severe public health problem and has been associated to the presence of human papiIlomavirus. Strategies are presently being tested which target the virus to attempt to control disease progress. Studies on the humoral and cell-mediated immunity of the papillomavirus infection have been useful in the development of a vaccine. Synthetic virus-like particles have been validated as vaccine against several animal papillomaviruses and used to map the seroepidemiology of the human papillomavirus infection, and define neutralizing antibodies. Induction of cellmediated immunity to HPV early proteins is bound to become a therapeutic approach to HPV infections. Recent advances have centered on directing the immune response to prevent infection, to virus-infected cells and to virally transformed cells, with favourable results.

Key words: cervix neoplasms; vaccines; immunotherapy; Mexico

* Trabajo presentado en el simposium: Perspectivas del desarrollo de vacunas en CaCu causado por el virus del papiloma humano. VII Congreso Nacional de Investigación en Salud Pública; 1997 marzo 2-5; Cuernavaca, Morelos, México.

(I) División de Virología Molecular, Centro de Investigación sobre Enfermedades Infecciosas, Instituto Nacional de Salud Pública, México.

(2) Laboratorio de Inmunología y Virología, Facultad de Ciencias Biológicas, Universidad Autónoma de Nuevo León, México.

Fecha de recibido: 18 de junio de 1997 - Fecha de aprobado: 18 de diciembre de 1997 Solicitud de sobretiros: Dr. Vicente Madrid Marina. División de Virología Molecular, Centro de Investigación sobre Enfermedades Infecciosas, Instituto Nacional de Salud Pública. Av. Universidad 655, colonia Santa María Ahuacatitlán, 62508 Cuernavaca, Morelos, México. 
E l cáncer cervicouterino $(\mathrm{CaCu})$ es una neoplasia muy frecuente en la población femenina; constituye $30 \%$ de los tumores malignos que se presentan en los habitantes de los países en desarrollo ${ }^{1}$ y es la segunda causa de muerte en mujeres en el mundo., ${ }^{2,3}$ Según la Organización Mundial de la Salud, se registran más de 500000 nuevos casos al año. En México es un grave problema de salud pública, pues en la última década ha sido el cáncer más frecuente en la población femenina. ${ }^{4}$ El factor de riesgo más importante para $\mathrm{CaCu}$ es la infección con virus del papiloma humano (HPV, por sus siglas en inglés) de alto riesgo; sin embargo, para la progresión de la neoplasia intraepitelial cervical (CIN) a cáncer invasivo ${ }^{5}$ se necesita la participación de otros factores, como alteraciones en proto-oncogenes (c-myc, ras y erbB2), anti-oncogenes $(p 53, R b)$ y la respuesta inmune del huésped. .-10 $^{-}$

\section{Inmunología contra la infección por el virus del papiloma humano}

Se conocen más de 80 tipos de HPV. De acuerdo con la similitud de las secuencias nucleotídicas del DNA viral, son especie específicos e infectan células epiteliales de mamíferos. Se han encontrado los tipos 6, 11, 16, 18, 33 y 35 en tumores genitales, llamados de alto riesgo, y específicamente el 16 es tres veces más frecuente en cáncer epitelial escamoso. ${ }^{11,12}$ La infección por HPV no es lítica y generalmente produce lesiones verrugosas planas o hiperqueratosas del epitelio escamoso sin inflamación local. Los HPV aparentemente han evolucionado para evadir la respuesta inmune, y la infección generalmente dura varios años. El ciclo de replicación de los HPV se lleva a cabo dentro de los queratinocitos; los viriones maduros escapan de la superficie epitelial infectada en los queratinocitos que se descaman. De esta manera, durante la infección hay poca presentación de antígenos virales al sistema inmune por células presentadoras de antígenos profesionales (tanto local, como sistémicamente). La lesión producida por los HPV de los genotipos trópicos para la mucosa anogenital, ocasionalmente se convierte en maligna, particularmente en los sitios de unión del epitelio escamo-columnar. La infección por HPV del cérvix humano es el principal antecedente del cáncer cervicouterino, por lo tanto se le ha dado prioridad a la infección por HPV como blanco para el desarrollo de vacunas profilácticas. La respuesta inmune contra los virus está dada tanto por la respuesta inmune humoral, como por la celular. Diversos estudios se han realizado para conocer los anticuerpos circulantes contra los HPV, pero son pocos los que se han llevado acabo para conocer la respuesta inmune celular. A continuación describiremos algunos estudios realizados a la fecha.
Respuesta inmune humoral contra los virus del papiloma humano

En HPV se han identificado genes de expresión temprana (E -early-) o tardía (L-late-). Los genes tempranos codifican para proteínas relacionadas con la replicación (E1), transcripción (E2) y transformación celular (E6 y E7). Los genes tardíos codifican para proteínas de la cápside (L1 y L2); en la figura 1 se esquematizan los genes que codifican para las proteínas del HPV-18.

A

Figura I. Virus del papiloma humano. A. Representación esQuemática de la ORGanización GENÓMICA DEL VIRUS DEL PAPILOMA HUMANO TIPO $18 .{ }^{13}$ B. REPRESENTACIÓN TRIDIMENSIONAL DEL VIRUS DEL PAPILOMA HUMANO

salud pública de méxico / vol.40, no.1, enero-febrero de 1998 
Anticuerpos contra proteínas de la cápside

La proteína principal de la cápside es L1, que comprende más de $90 \%$ de las proteínas del virión. La proteína menor es L2, cuya localización dentro del la cápside aún es incierta.

Los estudios sobre vacunas de HPV se han hecho principalmente en perros, conejos y bovinos. De estos estudios se ha podido demostrar que la infección con HPV se puede prevenir en estos animales al ser inmunizados con la proteína L1. Asimismo, la proteína L2 desnaturalizada sólo previene infecciones en bovinos y conejos. ${ }^{14-16}$ Aún no sabemos cuáles inmunizaciones protegen contra infecciones por la exposición a mucosas, como vía natural de la infección; además se desconoce cómo y dónde los anticuerpos sistémicos IgG neutralizan virus que solamente infectan células epiteliales.

En humanos, se ha demostrado la presencia de anticuerpos específicos o de reacción cruzada contra partículas parecidas a virus VLP -virus like particles-. De 50 a $60 \%$ de las mujeres infectadas con HPV tienen anticuerpos contra HPV-16 (VLP). A diferencia de otros tipos, los HPV-16 tienen algunas variantes y serológicamente presentan reacción cruzada. ${ }^{17,18}$

En CIN3 HPV-16+, estadio anterior a un cáncer cervical invasivo, se demuestran anticuerpos contra proteínas de la cápside; sin embargo, en cáncer invasivo HPV-16+, donde se están expresando proteínas tempranas y no viriones, no siempre se encuentran anticuerpos contra VLP de HPV..$^{19}$ Estudios de serorreactividad contra las VLP de los HPV sugieren que anticuerpos contra la cápside son inducidos durante infecciones severas o persistentes de HPV, y se pierden levemente después de que pasa la infección productiva. Los anticuerpos específicos contra la cápside, por consiguiente, no son marcadores confiables de infecciones por HPV-16 recientes o pasadas en un individuo.

\section{Anticuerpos contra proteinas virales tempranas}

Las proteínas tempranas de HPV comprenden seis de las proteínas codificadas por estos virus; éstas se expresan en forma coordinada y no se encuentran en los viriones maduros. En pacientes con cáncer cervical se ha encontrado producción de anticuerpos contra epítopos conformacionales más que lineales, de E6 y E7. ${ }^{20}$ Aunque anticuerpos contra E7 son más comunes en etapas avanzadas de cáncer, su significancia pronóstica es limitada. ${ }^{21,22}$

Respuesta inmune celular contra el virus del papiloma humano

Una de las respuestas más efectivas contra los virus se realiza por la inmunidad celular, que es mediada por células efectoras (CTL) como los macrófagos, las células asesinas naturales (NK) y los linfocitos T citotóxicos CD8+ (CTL), cuya actividad es regulada principalmente por los linfocitos T CD4+, los que se dividen en dos subpoblaciones de linfocitos $\mathrm{T}$ cooperadores (Th1 y Th2, por sus siglas en ingles), y son antagonistas entre sí en cuanto a la función de las citocinas que secretan. Los Th1 secretan interleucina (IL-2) e interferón gama (INF- $\gamma$ ), los que participan como los principales mediadores de la inmunidad celular contra microrganismos intracelulares y dirigen la defensa del huésped mediada por fagocitos. Las células Th2 secretan IL-4, IL-5 e IL-10, citocinas que suprimen la inmunidad mediada por células, por lo que Th2 es responsable de la defensa independiente de la fagocitosis. ${ }^{23}$ Así, una respuesta inmune celular antitumoral es inducida por citocinas de los linfocitos Th1 e inhibida por los Th2 (inmunosupresión). El papel de las citocinas en la respuesta inmune celular contra lesiones genitales producidas por el HPV ha sido poco estudiada. Las células NK y macrófagos están presentes en la mayoría de las lesiones; sin embargo, células de cáncer cervical y líneas célulares HPV+ son resistentes a las células NK. Se encontró gran proporción de linfocitos T CD3+, CD4; CD8, junto con la expresión del factor de necrosis tumoral (TNF- $\alpha$ ), IL-6 e IL-10 en $60 \%$ de las CIN. ${ }^{24}$ Por otro lado, existe gran interés en estudiar el papel de los linfocitos T CD4+ en la respuesta inmune antitumoral ${ }^{25-30}$ con el fin de desarrollar estrategias terapéuticas para pacientes con $\mathrm{CaCu}$ avanzado. En laboratorio hemos identificado la expresión de citocinas inmunosupresoras, tales como IL-10, IL-4 y TGF- $\beta$, en biopsias de pacientes con cáncer cervicouterino avanzado, positivo al HPV16, y no existe expresión de citocinas que aumentan la actividad antitumoral, como IL-2 e IL-12. Por lo tanto, estos resultados sugieren que existe un estado de inmunosupresión susceptible de ser manipulado por citocinas que inhiban la expresión de citocinas inmunosupresoras y aumenten la expresión de citocinas con actividad antitumoral.

\section{Relación entre HLA y cáncer cervicouterino}

El factor más importante en la regresión espontánea o en el progreso a carcinoma cervical invasor es la respuesta inmune celular. En esta respuesta el complejo principal de histocompatibilidad (MHC, en vertebrados específicamente, o HLA, en humanos) tiene la capacidad de presentar gran variedad de antígenos tumorales y virales, que son reconocidos por los linfocitos $\mathrm{T}$, los cuales actúan de una manera muy precisa para eliminar el tumor. Aunque la evidencia de la asociación entre HLA y cáncer cervicouterino ha sido controversial, hay 
estudios donde algunos haplotipos, clase I o II, están asociados positivamente con cáncer cervical invasor, mientras otros haplotipos actúan de manera negativa respecto al desarrollo del tumor, es decir, son protectores. Se han reportado ciertas alteraciones en la expresión de HLA en algunos tumores donde ésta se halla disminuida. En general, estos tumores son derivados de tejidos HLA+, mientras que otros con sobrexpresión de moléculas del HLA son derivados de tejidos que no la expresan o lo hacen de manera baja. ${ }^{31,32}$

Expresión de HLA clase I en tejidos normales, lesiones benignas y premalignas

El carcinoma de cérvix es derivado de epitelios HLA-I+. Hay varios mecanismos que pueden alterar la expresión del MHC-I, como son: inhibición en el transporte o glicosilación de HLA-I; mutación en los genes TAP; mutación o arreglos en el gen $\beta$-2-microglobulina; cambios en la metilación y la estructura de los genes clase I; alteraciones en la unión de los factores transcripcionales a elementos potenciadores o enhancers, y regulación negativa de la expresión de HLA-I por oncogenes Cis-Trans o por el HPV.

Se ha detectado que lesiones premalignas y malignas presentan una expresión negativa específica del locus HLA-B,C, clase I..$^{33}$ Se ha encontrado una expresión reducida de HLA-I en 70\% de los tumores estudiados, con un $50 \%$ de disminución en la expresión del alelo HLA-A2, 66\% en A3, 56\% en BW4 y $37 \%$ en BW6. ${ }^{34}$ También se ha analizado la expresión de HLA-I en linfocitos infiltrantes de cáncer cervical, donde hay una disminución de la expresión de HLA-I en $60 \%$ de las metástasis cervicales; sin embargo, sólo hay una disminución en $21 \%$ de los tumores primarios, ${ }^{35}$ lo que sugiere que la pérdida de la expresión de HLA I puede representar un mecanismo de escape de la respuesta mediada por linfocitos T CD8 citotóxicos y producir un aumento en el potencial metastásico de las células tumorales.

En algunos casos hay una pérdida en la expresión del haplotipo HLA-B7 en metástasis diseminadas de neoplasias cervicales, en donde se observa una variante de la proteína E6 de HPV-16, la cual tiene una alteración en uno de los epítopos que se unen a HLA-B7, mostrando un mecanismo de escape importante hacia la vigilancia inmunológica del HPV-16 en individuos HLA-B7. ${ }^{36}$

Otro de los mecanismos que podrían explicar la baja expresión de HLA-I en cáncer cervicouterino, es la mutación en TAP (proteína transportadora de antígenos); algunos estudios encuentran que la expresión de HLA-A y HLA-B por células tumorales es regulada negativamente en uno o más alelos, por lo menos en $73 \%$ de los carcinomas cervicales, y aproximadamente $50 \%$ de estos tumores presentó la pérdida de la expresión de TAP, sugiriendo que la inhibición de TAP por regulación negativa es una estrategia potencial de las células malignas para evadir la vigilancia inmune. ${ }^{37-39}$

También se ha observado la baja expresión de $\beta-2$ microglobulina; dos tercios de 42 muestras de epitelio cervical premaligno presentaron sobrexpresión de esta molécula, comparada con el epitelio normal; sin embargo, en 32 de 36 tumores invasivos disminuyó notablemente la sobrexpresión de $\beta$-2-microglobulina, lo que concuerda con la falta de expresión de HLA-I en tumores que ya han penetrado las membranas basales. ${ }^{40}$

Expresión de HLA clase II en lesiones premalignas y malignas

Las moléculas HLA-II no son expresadas normalmente en epitelio cervical, pero su expresión puede llevarse a cabo bajo diversas circunstancias patológicas, como lo es la inflamación, la transformación tumoral y la autoinmunidad.

\section{Expresión de alelos específicos $H L A-D r, D q$}

En epitelio escamoso ectocervical no neoplásico, la expresión del HLA-DR fue negativa consistentemente, aun en secciones mostrando significativa infiltración linfocitaria; sin embargo, se observa expresión de HLA-DR en epitelio glandular endocervical, epitelio escamoso metaplásico inmaduro y carcinoma invasivo. ${ }^{41}$ Existe una marcada ausencia en la expresión de HLA-DR en células cervicales normales, y escasa expresión en neoplasia intraepitelial escamosa de bajo grado pero en la neoplasia intraepitelial escamosa de alto grado; hay expresión de DR en los queratinocitos, lo que podría deberse a la produción de citocinas proinflamatorias liberadas por las células inmunocompetentes. ${ }^{42}$

En el análisis de la asociación de haplotipos clase II DR-DQ con carcinoma cervical-HPV-16+ en mujeres hispánicas, se encontró que el DRB1*1501-DQB1* 0602*0301*0303 y el DRB1* 0407-DR*0302 se asocian fuertemente al desarrollo del carcinoma cervical, mientras que en el haplotipo DR13 la asociación es negativa. ${ }^{43,44,45-48}$ Puesto que los haplotipos DQA* 0501DQB*0301 son más comunes en poblaciones hispánicas que en caucásicas, se concluyó que quizá la presencia de ciertos haplotipos HLA-II induce una respuesta inmune para epítopos específicos de HPV y afectan el riesgo de generar una displasia cervical grave y posteriormente un carcinoma cervical invasivo. En mujeres 
afroamericanas se encontró una asociación estadísticamente significativa entre un riesgo relativo de cáncer cervical y los haplotipos DQB1*0303 y DB1*0604, mientras que el haplotipo DQB1*0201 y el heterocigoto DQB1*0301/*0501 mostraron disminución en el riesgo de cáncer cervical. ${ }^{49}$ Estos estudios confirman lo encontrado en mujeres caucásicas, donde los alelos HLADQ3 también se asocian al riesgo de $\mathrm{CaCu}$. Resultados similares se reportan en un estudio de pacientes con cáncer cervical de células escamosas (SCCC), que presentan una frecuencia de los alelos DQA ${ }^{*} 030 \mathrm{X}$ y DQB1*0301. ${ }^{50}$

También existe una asociación significativa entre el haplotipo clase II DQW3 y SCCC HPV+, lo que sugiere que estas pacientes tienen una inhabilidad para eliminar la infección por HPV que las predispone a desarrollar el SCCC. ${ }^{51}$ Asimismo existe una ligera asociación de cáncer de células escamosas y HLA-DQB12; hay aumento no significativo en la expresión de los subtipos de HLA B12 (HLA-B44/45), y se supone que este aumento probablemente es secundario a HLADQW3 ${ }^{52} \mathrm{~A}$ pesar de los análisis hechos, la asociación entre HLA y carcinoma cervical es controversial, y aún hace falta perseverar en los estudios para identificar alelos HLA o haplotipos que tengan susceptibilidad aumentada al cáncer cervical asociado al HPV de alto riesgo.

\section{Perspectivas para el desarrollo de vacunas}

Para desarrollar una vacuna contra el cáncer cervicouterino se deben considerar diversos aspectos de la inmunología contra el cáncer y contra los virus del papiloma. Una vez analizada la respuesta inmune humoral y celular, así como la presentación de antígenos tumorales y virales por moléculas HLA, es importante definir las estrategias para elaborar las vacunas. Así, es necesario precisar que existen dos tipos de vacunas: a) las profilácticas, y b) las terapéuticas. Las primeras deben ser aplicadas antes de la infección con la finalidad de producir anticuerpos neutralizantes contra el $\mathrm{HPV}$, mientras que las segundas serán usadas en los estadios subsecuentes a la infección, para evitar la replicación del virus, contra proteínas tempranas del virus, o bien, para controlar el crecimiento tumoral cuando el HPV está integrado.

\section{Vacunas profilácticas}

El objetivo principal de las vacunas profilácticas es prevenir la infección por HPV, así como el desarrollo de lesiones en individuos infectados con el virus. Las va- cunas que protegen de la infección por HPV están dirigidas a producir anticuerpos neutralizantes contra proteínas estructurales L1 y L2 de la cápside viral de HPV. El uso de proteínas de fusión L1 y L2, que inducen la producción de anticuerpos neutralizantes, ha demostrado prevenir infecciones con HPV; ${ }^{53,54}$ se han usado partículas sintéticas de algunos tipos de HPV dando mejores resultados que las proteínas de fusión. Otra estrategia para producir respuesta inmune neutralizante contra las proteínas de la cápside viral ha sido la producción por ingeniería genética de proteínas ensambladas incapaces de infectar por sí mismas a una célula viva (VLP), las que están compuestas solamente de las proteínas externas de membrana L1 o L1/L2; esta técnica es muy útil ya que la producción de partículas virales in-vitro no es sencilla. ${ }^{55,56}$

Se conoce poco acerca de los factores implicados en la progresión hacia la enfermedad clínica, y debido a la gran cantidad de tiempo que se necesita para que ésta se desarrolle, la vacunación profiláctica es menos atractiva para $\mathrm{CaCu}$ que para infecciones por HPV no oncogénicas, las que desarrollan lesiones rápidamente. Hay varias consideraciones respecto a la utilización de este tipo de vacunas, ya que no está claro si la infección es debida a partículas virales libres o a partículas que permanecen encerradas en las células escamosas, las cuales protegen de la acción de los anticuerpos; también deben realizarse vacunas dirigidas contra HPV específicos o contra un grupo de virus, ${ }^{57,58}$ ya que hay casos de infecciones mixtas, además de que la mayoría de las infecciones por HPV son asintomáticas y / o clínicamente no detectables. La identificación de individuos probables para la aplicación de vacunas profilácticas se realiza principalmente por ensayos serológicos, pero es difícil identificar a los verdaderos seronegativos, ya que hay varios factores que influyen en estos resultados; más aún, debido a que estas infecciones son a nivel de mucosas, es necesario produccir vacunas que induzcan inmunidad de tipo $\operatorname{IgA}$, pero que a la vez sea una inmunidad persistente en virtud de que es necesaria la persistencia de la infección del HPV para que se desarrolle cáncer invasor. ${ }^{59}$

\section{Vacunas terapéuticas}

El objetivo principal de este tipo de vacunas es inducir inmunidad celular específica que permita la regresión de lesiones establecidas o aún la regresión de tumores malignos. Las vacunas terapéuticas que se han utilizado, han sido vacunas basadas en vectores, vacunas tumorales y vacunas basadas en péptidos. ${ }^{60-65}$ En las primeras se utilizan vectores virales, tales como el vaccinia virus, el cual tiene una gran capacidad de in- 
serción genética y promueve la producción de grandes cantidades de proteínas recombinantes. ${ }^{66,67}$ Las vacunas tumorales consisten en la transfección de células tumorales con genes como MHC-I, moléculas coestimuladoras, citocinas como el INF- $\gamma$, y factores de crecimiento. ${ }^{68-72}$ En cuanto a las vacunas basadas en péptidos, en sistemas murinos se han evaluado péptidos que contienen epítopos para CTL, los que protegen de la producción de tumores dirigidos contra HPV-16. ${ }^{60}$ En humanos ya se han identificado péptidos específicos de E6 y E7 restringidos a CTL y presentados por los alelos HLA-A más comunes. ${ }^{73,74}$ La continua búsqueda de acarreadores eficientes y epítopos importantes para MHC-I y MHC-II ayudará al futuro desarrollo de vacunas con péptidos específicos.

Vacunas terapéuticas para evitar la replicación intracelular del HPV

Debido a que los anticuerpos neutralizantes no pueden reaccionar con los viriones intracelulares, una vacuna cuya función sea eliminar la replicación viral debe estimular linfocitos citotóxicos dirigidos contra sitios específicos (epítopos) de proteínas procesados intracelularmente y presentados en el contexto del MHC-I. Lo ideal de este tipo de vacunas sería producir una respuesta celular tanto para células diferenciadas infectadas viralmente, como para células madre epiteliales, dirigidas principalmente hacia proteínas L1, L2 y E4, en el caso de las células diferenciadas, y contra E1 y E2 para las células madre. Otra vacuna alternativa es aquella que produzca hipersensibilidad de tipo retardada. ${ }^{75}$

Vacunas terapéuticas para controlar tumores asociados al $H P V$

Las proteínas E6 y E7, que son necesarias para la transformación celular y que funcionan como antígenos tumorales principalmente, son el blanco para vacunas que ayudarán a controlar tumores inducidos por HPV. ${ }^{76-81}$ También se han probado proteínas recombinantes de E6 y E7, produciendo tanto prevención como retraso del desarrollo de tumores en ratones. ${ }^{82}$

Además actualmente un número de estrategias para inmunomodular el $\mathrm{CaCu}$, como son las vacunas con células tumorales modificadas por ingeniería genética ex-vivo para secretar citocinas moduladoras específicas o moléculas estimuladoras, sugiere la posibilidad de inmunoterapia por inducción local o dirigida. Tal es el caso de IL-6, IL-2, INF- $\gamma$ y B7; $27,69,71,72,83-87$ asimismo, la administración de CTL que induzcan la secreción de IL-2; la utilización de la proteína LAMP, para dirigir el procesamiento de E7 a compartimientos lisosomales y endosomales para ser presentados vía MHC-II, y por último, la inoculación subcutánea de antígenos tumorales que son presentados por células dendríticas que estimulan CTL. ${ }^{88-90}$

Los parámetros a considerarse en este tipo de vacunas serían primeramente el tipo de adyuvantes a utilizar, ya que se requieren de aquellos que produzcan respuestas de CTL tipo Th1 más que Th2. En segundo lugar, la utilización de un sistema adecuado para la medición de la respuesta de las CTL en lesiones más que en sangre periférica; en tercero, determinar la duración de la memoria de las CTL contra HPV, y finalmente, determinar la cantidad de retos a manejar, asî como la vida media de los vectores que se usan. ${ }^{74}$

Se han realizado gran variedad de estudios con el fin de proporcionar conocimiento del papel que tienen las proteínas tempranas en la generación de vacunas profilácticas; asimismo se han hecho análisis de diversos aspectos para el desarrollo de inmunoprofilaxis y de inmunoterapia. ${ }^{91-95}$ Finalmente, consideramos que para la elaboración de una vacuna profiláctica o terapéutica se precisa como requisito indispensable el conocimiento de la respuesta inmune local de cada paciente. ${ }^{96}$ Así, nuestro interés se ha centrado en el análisis de la respuesta inmune celular local, en donde hemos identificado, con el uso de técnicas de biología molecular, la expresión aumentada de citocinas inmunosupresoras por células del cáncer cervical y la falta de producción de citocinas con actividad antitumoral..$^{96, *}$, De tal forma que nuestra propuesta es hacer un diagnóstico de la respuesta inmune celular local, identificar el problema y aplicar la inmunoterapia adecuada a cada paciente, dependiendo del grado de la alteración de dicha respuesta.

\section{Conclusiones}

El impresionante progreso en el entendimiento de la respuesta inmune celular y de otros aspectos de la respuesta inmune del hospedero contra la infección del HPV, así como el desarrollo tanto de diversos tipos de vacunas y estrategias de inmunoterapia como de muchos de los resultados obtenidos en estas investigaciones, han permitido un futuro prometedor para implementar medidas terapéuticas que involucran la respuesta

\footnotetext{
* Alcocer-González JM, Tamez R, Gariglio P, Hernández-Pando R, Madrid-Marina V. Expression of Interleukin-10 in human cancer cells infected with HPV-16. Cancer Res 1997. Documento no publicado.

‡ Alcocer-González JM, Tamez R, Gariglio P, Madrid-Marina V. Th2 cytokine expression pattern in cancer cells infected with HPV-16. Immunology 1997. Documento no publicado.
} 
inmune en el tratamiento del cáncer cervicouterino. Sin embargo, mientras no se demuestre la eficacia de los anticuerpos neutralizantes del HPV, los datos provenientes de modelos animales quedarán como simple aproximación de vacunas profilácticas. Más aún, el diseño de ensayos clínicos es complicado, ya que hay que considerar: a) qué población femenina vamos a vacunar; b) cuáles serán los estudios a realizar, y c) cuál es el tiempo de evaluación del estudio para validar la eficacia de la vacuna. Tomando en cuenta que sólo del HPV-16 existen múltiples variantes que determinan el riesgo de una neoplasia cervical y las estrategias del diseño de vacunas, ${ }^{97-100}$ realizar una vacuna para un subtipo de HPV resulta más complicado.

El diseño de un sistema de inmunoterapia contra cáncer cervicouterino avanzado asociado al HPV deberá hacerse aumentando la respuesta inmune celular, preferentemente contra proteínas tempranas del HPV en el epitelio infectado. Se deberán establecer estrategias con manipulaciones inmunológicas, que eliminen el componente Th2 (inmunosupresión), activando la respuesta de Th1 y, por lo tanto, aumentando la actividad antitumoral de los macrófagos, células NK y linfocitos $\mathrm{T}$ citotóxicos contra las células del cáncer cervicouterino. La persistencia de las proteínas E6/E7 en las células neoplásicas permitirá diseñar un sistema de vacuna terapéutica dirigida contra estos antígenos, que aumente la presentación antigénica mediante las moléculas HLA, con el uso de INF- $\gamma$ e IL-12. Otra estrategia sería la del uso de citocinas generadas por ingeniería genética tipo Th1, tales como IL-2 e INF- $\gamma$ recombinantes, que induzcan la producción de IL-2 e IL-12 endógenas, eliminen la producción de IL-10 e IL-4, aumenten la actividad antitumoral, desaparezcan el tumor y, por lo tanto, aumenten la sobrevida de los pacientes con cáncer cervicouterino avanzado. Esta estrategia puede lograrse también con el uso de los genes que codifican para la IL-2 e INF- $\gamma$, en diversos vectores de clonación y en diversos vehículos de liberación, como adenovirus o liposomas, lo que eventualmente nos llevará a la terapia génica contra el cáncer cervicouterino humano.

\section{Referencias}

I. Mitchell M, HittelmanWN, HongWK, Schottenfeld D.The natural history of cervical intraepithelial neoplasia: An argument for intermediate endpoint biomarkers. Cancer Epidemiol Biomarkers Prev 1994;3:619-626.

2. Shiffman HM, MPH, Brinton AL. The epidemiology of cervical carcinogenesis. Cancer 1995; 10:1888-1901.

3. BrokerTR, Botchan M. Papillomaviruses: Retrospectives and prospectives. Cancer Cell 1986;4:17-35.
4. Escandón-Romero C, Benítez-Martínez MG, Navarrete-Espinoza J, Vázquez-Martínez JL, Martínez-Montaño OG, Escobedo-de la Peña J. Epidemiología del cáncer cervicouterino en el Instituto Mexicano del Seguro Social. Salud Publica Mex 1992;34:607-6I4.

5. Riou G, Le MG, Le Doussal V, Barrios M, George M, Haie C. C-myc proto-oncogene expression and prognosis in early carcinoma of the uterine cervix. Lancet 1987;2:761-763.

6. Muñoz N, Bosch FX, Sanjosé S, Shah KV.The role of HPV in the etiology of cervical cancer. Mutat Res 1994;305:293-30I.

7. Cullen A, Reid R, Campion M, Loincz AT. Analysis of the physical state of different HPV DNAs in intraepithelial and invasive cervical neoplasia. J Virol 1991;65:606-612.

8. Schiffman MH, Bauer HM, Hoover RN, Glass AG, Cadell DM, Rush BB et al. Epidemiologic evidence showing that HPV infection causes most cervical intraepithelial and invasive neoplasia.J Natl Cancer Inst 1993;85:958-964. 9. Pinion SB, Kennedy JH, Muller RW, MacLean AB. Oncogene expression in cervical intraepithelial neoplasia and invasive cáncer of cervix. Lancet 1991;337:819-820.

10. Mitra AB, MurtyVV, Pratap M, Sodhani P, Chaganti RS. erbB2 (HER/neu) oncogene in frequently amplified in scamous cell carcinoma of the uterine cervix. Cancer Res 1994:54:637-639.

I I. De Villiers E. Heterogeneity of human Papillomavirus group. J Virol 1989;63:4894-4903.

12.Van Ranst M, Kaplan JB, Burk RD. Phylogenetic classification of human papillomaviruses: Correlation with clinical manifestation. J Gen Virol 1992;73:2653-2660.

13. Alvarez-Salas LM, López-Bayghen E. Regulación genética de los papilomavirus humanos genitales. Salud Publica Mex 1995;37(3):240-247. 14. Suzich JA, Ghim SJ, Palmer-Hill, White WI, Tamura JK, Bell JA et al. Systemic immunization with papillomavirus $L I$ protein completely prevents the development of viral mucosal papillomas. Proc Natl Acad Sci U S A 1995;92:111553-II557.

15. Jensen KU, Rosolowsky M, Shultz LD, Markus HZ, Cook JC, Donnelly JJ et al. Vaccination with yeast-expressed cottontail rabbits from CRPVinduced papilloma formation. Vaccine 1995; 13:1509-1514.

16. Kirnbauer R, Chandrachud LM, O'Neil BW,Wagner ER, Grindlay G], Armstrong AA et al. Virus-like particles of bovine papillomavirus type 4 in prophylatic and therapeutic immunization. Virology 1996;219:37-44.

17. Yamada T, Wheeler CM, Halpern AL, Stewart ACM, Hildesheim A, Jenison SA. Human papillomavirus-16 variant lineages in United States populations characterized by nucleotide sequence analysis of the $E 6, L 2$, and LI coding segments. JVirol 1995;669:7743-7753.

18. Cheng G, Icenogle JP, Kirnbauer R, Hubbert NL, St Louis ME, Han CL et al. Divergent human papillomavirus type 16 variants serologically crossreactive.J Infect Dis 1995; I72:1584-1587.

19. Nonnenmancher B, Hubbert NL, Kirnbauer R, Shah KV, Muñoz N, Bosch FX et al. Serologic response to human papillomavirus- 16 virus-like particles in HPV-16+ invasive cervical cancer and cervical intraepithelial neoplasia grade III patients and controls from Colombia and Spain.J Infect Dis 1995; 172:19-24.

20. Nindl I, Benítez-Bribiesca L, Berumen J, Farmanara N, Fisher S, Gross $\mathrm{G}$ et al. Antibodies against linear and conformational epitopes of the human papillomavirus (HPV) type 16 and E7 oncoproteins in sera of cervical cancer patients. Arch Virol 1994; I37: 34I-353.

21. Gaarenstroom KN, Kenter GG, Bronfer JMG, Korse CM, Gallee MPW, Hart AAM et al. Prognostic significance of serum antibodies to human papillomavirus-16 E4 and E7 peptides in cervical cancer. Cancer 1994;74:2307-23।3.

22. Baay MFD, Duk JM, Burger MPM, De Bruijn HWA, Stolz E, Herbrink P. Follow-up antobody responses to human papillomavirus type 16 E7 in patients treated, for cervical carcinoma. J Med Virol 1995;45:342-347.

23.Abbas KA, Litchtman HA, Pober SJ. Cellular and molecular immunology. 2a. edición. Filadelfia: W.B. Sanders, 1991. 
24. Crowley-Nowick P, Bell MC, Bull R, Edwards RP, Partridge EE. Cytokine expression by $T$ cells isolated from cervical intraepithelial neoplasia lesions. 12th. International Papillomavirus Conference; 1993 septiembre 20-30; Baltimore (MD); Abstracts Book: 7.

25.Tzyy-Choou W. Immunology of the human papillomavirus in relation to cancer. Curr Opin Immunol 1994;6:746-754.

26. Golumbek PT, Lazenby AJ, Levitsky HI, Jaffe LM, Karasuyama H, Baker $M$ et al. Treatment of establishied cancer by tumor cells ingeneered to secrete interleukin-4. Science 199|;254:7|3-7|6.

27. Dranoff G, Jaffee E, Lazenby AJ, Golumbek PT, Levitsky HI, Brose K et al. Vaccination with irratiated tumor cells ingeenered to secrete murine granulocyte-macrophage colony-stimulating factor stimulates potent specific, and long-lasting anti-tumor immunity. Proc Natl Acad Sci U S A 1993;90:3539-3543.

28. Topalian SL, Rivoltini L, Macini M, Ng J, Hartzman RJ, Rosenberg SA. Melanoma-specific CD4+ T lymphocytes recognize human melanoma antigens processed and presented by Ebstein-Barr virus-transformed $B$ cells. Int J Cancer 1994;58:69-79.

29. Topalian SL, Rivoltini L, Mancini M, Markus NR, Robbins PF, KawakamiY et al. Human CD4+ $T$ cells specifically recognize a shared melanomaassociated antigen encoded by the tyrosine gene. Proc Natl Acad Sci U S A 1994;91:946I-9465.

30. Topalian SL. MHC class II restricted tumor antigens and the role of CD4+ T cells in cancer immunotherapy. Curr Opin Immunol 1994;6:74I745 .

31. Garrido F, Cabrera T, Concha A, Glew S, Cabello RF, Stern LP. Natural history of HLA expression during tumor development. Immunol Today 1993; 14:491-499.

32. Herrington CS. Human papillomaviruses and cervical neoplasia. Interation of HPV with other factors. J Clin Pathol 1995;48: I-6.

33. Cromme FV, Meijer CJLM, Snijers PJF et al. Analisys of HLA-DR expression on keratinocytes in cervical neoplasia. $\mathrm{Br} J$ Cancer 1993;67:1372-1380.

34. Hilders CG, Houbiers JG, Krul EJ, Fleuren GJ. The expression of histocompatibility-related leukocyte antigens in the pathway to cervical carcinoma. Am J Clin Pathol 1994;10I(I):5-12.

35. Hilders CG, Muñoz IM, Nooyen Y, Fleuren GJ. Altered HLA expression by metastasic cervical carcinoma cells as a factor in impaired immune surveillance. Gynecol Oncol 1995; 57(3):366-375.

36. Ellis JR, Keating PJ, Baird J, Hounesll EF, Renouf DV, Rowe M et al. The association of an HPV 16 oncogene variant with HLA-B7 has implications for vaccine desing in cervical cancer. Nat Med 1995;5:464-470.

37. Cromme FV, Airey J, Heemels MT, Ploegh HL, Keating PJ, Meijer CJ et al. Loss of transporters protein encoded by the TAP-I gene, in highly correlated with loss of HLA expression in cervical carcinomas.J Exp Med 1994; I79(I):335-340.

38. Cromme FV, Van Bommel PF, Walboomers JM, Gallee MP, Stern PL, Kenemans $P$ et al. Differences in MHC and TAP-I expression in cervical cancer lymph node metastases as compares with the primary tumors. $\mathrm{Br}$ J Cancer 1994; 69(6): ||76-||8|.

39. Keating PJ, Cromme FV, Duggan-Keen M, Snijers PJ, Walboomers JM, Hunter RD et al. Frequency of down- regulation of individual HLA-A and $B$ alleles in cervical carcinomas in relation to TAP-I expression. $\mathrm{Br}$ J Cancer 1995;72(2):405-4I I.

40. Petersen BL, Petersen CL, Braendstrup O, Mourutsen S, Engel AM, Svane IM et al. Expression of beta 2-microglobulin by premalingnant epithelium. APMIS 1993;10I(7):529-536.

4I. Raju GC, Thel M, Wee A. The expression of HLA-DR antigen in cervical neoplasia. Cancer Detect Prev 1994; I8(5):367-373.

42. Coleman N, Stanley MA. Analysis of HLA-DR expression on keratinocytes in cervical neoplasia. Int J Cancer 1994:56(3):314-319.

43. Apple RJ, Erlich HA, Klitz W, Manos MM, Becker TM, Wheeler CM. HLA DR-DQ associations with cervical carcinoma show papillomavirustype specificity. Nat Genet 1994; 6(2):157-162.
44. Apple RJ, Becker TM, Wheeler CM, Erlich HA. Comparison of human leukocyte antigen DR-DQ disease associations found with cervical dysplasia and invasive cervical carcinoma. J Natl Cancer Inst 1995;87(6):427-436. 45. Wank R, Meulen JT, Luade J, Eberhardt HC, Pawlita M. Cervical intraepithelial neoplasia, cervical carcinoma, and risk for patients with HLADQBI*0602*30I, *0303 alleles [comment]. Lancet 1992;342(8870):553. 46. Odunsi K, Terry G, Ho L, Bell J, Cuzick J, Ganesan TS. Association between HLA DQBI*03 and cervical intra-epitelial neoplasia. Mol Med |995;I(2):|6|-|7|.

47. Vandenvelde C, De Foor M,Van Beers D. HLA.DOBI*03 and cervical neoplasia grades I-III (letters). Lancet I993;34I(8854): I2I5.

48.Vandenvelde C, De Foor M,Van Beers D. Precision about the association between cervical carcinoma and HLA-DQBI*03 alleles [comment]. Lancet 1993;34(8854): 1215.

49. Gregoire L, Lawrence WD, Kukuruga D, Eisenbrey AB, Lancaster WD. Association between HLA-DQBI alleles and risk for cervical cancer in African-American women. Int J Cancer 1994;57(4):504-507.

50. Helland A, Borresen AL, Krinstensen G, Ronningen KS. DQAI and $\mathrm{DQBI}$ genes in patients with squamous cell carcinomas of the cervix: Relationship to human papillomavirus infecton and prognosis. Cancer Epidemiol Biomarkers Prev 1994;3(6):479-486.

51. MehalWZ, LoYM, Herrington CS, Evans MF, Papadopoulos MC, Odunis $\mathrm{K}$ et al. Role of human papillomavirus in determining the HLA associated risk of cervical carcinogenesis. J Clin Pathol 1994;47(I2):1077-108I.

52. Wank R, Thomssen C. High risk of squamous cell carcinoma of the cervix for women with HLA-DQW3. Nature 1991;352:723-725.

53. Christensen ND, Kreider JW, Kan NC, DiAngelo SL.The open reading frame L2 of cottontail rabbit Papillomavirus contains antibody-inducing neutralizing epitopes. Virology 1991; 181:572-579.

54. Hagensee M, Galloway D. Growing human papillomaviruses and virus like particles in the laboratory. Papillomavirus Rep 1993;4:I2I-I 24.

55. Hofmann KJ, Neeper MP, Markus HZ, Brown DR, Müller M, Jansen KU. Secuence conservation with the major capsid protein of human papillomavirus (HPV) type 18 and formation of hpv- 18 virus-like particles in Sacharomyces cerevisiae. I Gen Virol 1996:77:465-468.

56. Heino P, Diller J, Schwartz S. Human papillomavirus type 16 capsid proteins produced from recombinant Semliki forest virus assemble into virus like particle. Virology 1995;214:349-359.

57. Hagensee ME, Yaegashi N, Galloway DA et al. Self-assembly of human papillomavirus type I capsids by expression of the LI protein alone or by coexpression of the LI and L2 capsid protein. JVirol 1993;67:315-322.

58. Muñoz NL, Crawford P, Coursaget P. HPV vaccine and their potential use in the prevention and treatment of cervical deoplasia papillomavirus. Reproduction 1995;6:54-55.

59. Ruffin MT, Ogaily MS, Johnston CM, Gregoire L, Lancaster WD, Brener DE. Surrogate endpoint biomarkers for cervical cancer chemoprevention trials. J Cell Biochem 1995;23: I |3-124.

60. Feltkamp MC, Smiths HL, Viesboom MP, Minnaar RP, De Johgh BM, Brijfhout JW et al. Vaccination with cytotoxic $T$ lymphocytes epitopecontaining peptide protects against a tumor induced by human papillomavirus type 16 transformed cells. Eur J Immunol 1993;23:22422249.

61. Gao L, Chain B, Sinclair C, Crawford L, Zhou J, Morris J et al. Immune response to human papillomavirus type $16 \mathrm{E} 6$ gene in a live vaccinia vector. J Gen Virol 1994;75:157-164.

62. Meneguzzi G, Cerni C, Kieny MP, Lathe R. Immunization against human papillomavirus type 16 tumor cells with recombinant vaccinia viruses expresing E6 and E7.Virology 1991;181:62-69.

63. Chen LP, Thomas EK, Hu SL, Hellstrom I, Hellstrom KE. Human papillomavirus type 16 nucleoprotein E7 is a tumor rejection antigen. Proc Natl Acad Sci U SA 1991;88:1 10-114.

64. Chen LP, Ashe S, Brady WA, Hellstrom I, Hellstrom KE, Ledbetter JA et al. Costimulation of antitumor immunity by the B7 counterreceptor for the T lymphocyte molecules CD28 and CTLA-4. Cell 1992;7I: 1093-I I02. 
65. Chen L, McGowan P, Ashe S, Johnston J, Li YW, Hellstrom I et al. Tumor immunogenicity determines the effect of B7 costimulation on T cell mediated tumor immunity.J Exp Med 1994;179:523-532.

66. Boursnell ME, Retherford E, Hickñing JK, Rollinson EA, Munro AJ, Rolley $\mathrm{N}$ et al. Construction and characterization of a recombinantvaccinia virus expressing human papillomavirus proteins for immunotherapy of cervical cancer. Vaccine 1996; I4(I6): I 485-I494.

67. Boryslewicz LK, Flander A, Nimako M, Man S, Wilkinson GW, Westmoreland $D$ et al. $A$ recombinant vaccinia virus encoding human papillomavirus types 16 and $18, \mathrm{E} 6$ and $\mathrm{E} 7$ proteinsas immunotherapy for cervical cancer. Lancet 1996;347:1523-1527.

68. Hui L, Grosveld F, Festenstein H. Rejection of transplantable AKR, leukemia cells following MHC DNA-Mediated cell transformation. Nature 1984;3| |:750-752.

69. Tanaka K, Isselbacher K, Khnoury G, Jay G. Reversal of oncogenesis by the expression of a major histocompatibility complex class I gene. Science 1984;228:26-30.

70. Watanabe Y, Kuribayashi K, Miyatake S, Nishihara K, Nakayama E, Taniyama $T$ et al. Exogenous expression of mouse interferon $r$ CDNA in mouse neuroblastoma C 1300 cells results in reduced tumorogenicity by augmented antitumor immunity. Proc Natl Acad Sci U S A 1989;86:94569460

7I. Pardoll D. New strategies for ehancing the immunogenicity of tumors. Curr Opin Immunol 1993;5:719-725.

72. Dranoff G, Jaffe E, Lazenby A, Golumbek P, Levitsky H, Brose K et al. Vaccination with irradiated tumor cells engineered to secrete murine granulocyte-macrophage colony-stimulating factor stimulates potent, specific, and long- lasting antitumor Immunity. Proc Natl Acad Sci U S A 1993;90:3539-3543.

73. Ressing ME, Sette A, Brandt RMP, Ruppert J,Wentworth P, Hartman M et al. Human CTL epitopes encoded by human papillomavirus type 16 E6 and E7 identified through in vivo and in vitro immunogenicity studies of HLA A*020I binding peptides. J Immunol 1995;154:5934-5943.

74. Ressing ME, Van Driel WJ, Celis E, Sette A, Brandt RMP, Hartman M et al. Occasional memory cytotoxic T-cell responses of patients with human papillomavirus type 16 positive cervical lesions against a human leucocyte antigen $A * 020$ I restricted E7 encoded epitope. Cancer Res 1996;56:582588.

75. Chambers MA, Stacey SN, Arrand JR, Stanley MA. Delayed type hypersensibility response to human papillomavirus type $16 \mathrm{E} 6$ protein in a mouse model.J Gen Virol 1994;75:165-169.

76. Mackett M, Smith G, Moss B. Vaccinia virus: A selectable eukaryotic cloning and expression vectors. Proc Natl Acad Sci U S A 1982;79:74157419.

77. Jenkins O, Cason J, Burke KL, Lunney D, Gillen A, Patel D et al. An antigen chimera of poliovirus induces antibodies against human papillomavirus type 16. JVirol 1990;64:120I-1206.

78. Tindle RW, Herd K, Londono P, Fernando GJP, Chatfield SN, Malcom K et al. Chimeric Hepatitis B core antigen particles containing B and Th epitopes of human Papilloma virus type 16 E7 protein induce specific antibody and Thelper responses in immunised mice.Virology 1994;200:547557.

79. Pozzi G, Contoni M, Oggioni MR, Manganelli R, Tommasino M, Cavalieri $\mathrm{F}$ et al. The delivery and expression of a heterologous antigen on the surface of streptococci. Infect Immun 1992;60:1902-1907.

80. Crawford L. Prospects for cervical cancer vaccines. Cancer Surv 1993;16:215-229.

8I. Hui L, Grosveld F, Festenstein H. Rejection of transplantable AKR leukemia cells following MHC DNA mediated cells transformation. Nature |994;3| |:750-752.
82. Meneguzzi G, Cerni C, Kieny MP, Lathe R. Immunization against human papillomavirus type 16 tumor cells with recombinant vaccinia viruses expressing E6 and E7.Virology 1991;181:62-69.

83. Watanabe $Y$, Kuribayashi K, Miyatake S, Nishihara K, Nakayama E, Taniyama $T$ et al. Exogenous expression of mouse interferon $\gamma$ CDNA in mouse neuroblastoma $\mathrm{Cl} 300$ cells results in reduced tumorigenicity by augmented anti-tumor immunity. Proc Acad Sci U S A 1989;86:9456-9460. 84.Wu TC. Immunology of the human papillomavirus in relation to cancer. Curr Opin Immunol 1994;6:746-754.

85. Rock K, Fleischacker C, Gamble S. Peptide-priming of cytotoxic T cell immunity in vivo using $\beta 2$ - microglobulin as an adyuvant. J Immunol 1993; 150:1244-1252.

86. Iglesias M, PlowanGD, Woodworth CD. Interleukin-6 and interleukin soluble receptor regulate proliferation of normal, human papillomavirusimmortalized and carcinoma-derived cervical cells in vitro. Am J Pathol 1995;46:944-952.

87. Ramsay AJ, Leong KH, Boyle D, Ruby J, Ramshaw IA. Enhancement of mucosal IgA responses by interleukins 5 and 6 encoded in recombinant vaccine vectors. Reprod Fertil Dev 1994;6:389-392.

88. Wu TC, Guamieri FG, Staveley-O'Carroll KF, Viscidi RP, Levitsky H, Hedrick $L$ et al. Engineering an intracellular pathway for major histocompatibility complex class II presentation of antigens. Proc Natl Acad Sci U SA 1995;92:I|67|-II675.

89. Lin KY, Guarnieri FG, Staveley-O' Carroll KF, Levitsky H, Pardoll DM, WuTC.Treatment of established tumors with a novel vaccine that enhances mayor histocompatibility class II presentation of tumor antigen. Cancer Res 1996;56:21-26.

90. Ossevoort MA, Feltkamp MCW,Van Veen KJH, Melief CJM, Kast WM. Dendritic cells as carriers for a cytotoxic T-lymphocytes epitope based peptide vaccine in protection against a human papillomavirus type 16 induced tumor. J Immunother 1995; |8:86-94.

9I. Jarrett W, Smith K, O'Neil B, Gaukroger J, Chandrachud L, Grindlay Gea. Studies on vaccination against papillomavirus es: Prophylactic and therapeutic vaccination with recombinant structural proteins. Virology 199|; 184:33-42.

92. Lin Y L, Borenstein LA, Selvakumar R, Ahmed R, Wettstein FO. Effective vaccination againt papilloma develoment by immunization with L1 ○ L2 structural protein of cottontail rabbit papillomavirus. Virology 1992;187:612-619.

93. Kirnbauer R, Booy F, Cheng N, Lowy DR, Schiller JT. Papillomavirus LI major capside protein self-assembles into virus-like particles that are highly immunogenic. Proc Natl Acad Sci U S A 1992;89:12180-12184.

94. Kirnbauer R, Tanb J, Greenstone H, Roden R, Dorst M, Gissmann L et al. Efficient self-assembly of human papillomavirus type $16 \mathrm{LI}$ L-2 into virus-like particles. JVirol 1993; 67:6929-6936.

95. Cason J, Khan SA, Best JM. Towards vaccines against human papillomavirus type-16 genital infections. Vaccine 1993; II:603-611.

96. Barrera-Rodríguez R, Peralta-Zaragoza O, Madrid-Marina V. Bases moleculares de la inmunología del cancer. Salud Publica Mex 1995;37:344353.

97. Yamada T, Manos M, Peto J, Greer CE, Muñoz N, Bosh FX. Human paillomavirus type 16 sequence variation in cervical cancers: $A$ worldwide perspective. J Virol 1997;71:2463-2472.

98. Tindle RW. Human papillomavirus vaccines for cervical cancer. Curr Opin Immunol 1996;8:643-665.

99. Wheeler CM. Preventive vaccines for cervical cancer. Salud Publica Mex 1997;39(4):283-287.

100. Berumen J,Villegas N.Vacunas terapéuticas recombinantes contra el cáncer cervicouterino. Salud Publica Mex 1997;39(4):288-297. 